\title{
Low-glycemic index diet may improve insulin sensitivity in obese children
}

\author{
Chonnikant Visuthranukul', Pathama Sirimongkol', Aree Prachansuwan ${ }^{2}$, Chandhita Pruksananonda $^{3}$ and Sirinuch Chomtho ${ }^{4}$
}

BACKGROUND: A low-glycemic index (Gl) diet may be beneficial for weight management due to its effect on insulin metabolism and satiety.

METHODS: Obese children aged 9-16 y were randomly assigned either a low-Gl diet or a low-fat diet (control group) for 6 mo. Body composition changes were measured by dualenergy $\mathrm{X}$-ray absorptiometry and bioelectrical impedance analysis. Insulin sensitivity was measured by fasting plasma glucose and insulin.

RESULTS: Fifty-two participants completed the study (mean age: $12.0 \pm 2.0$ y, 35 boys); both groups showed significantly decreased BMI $z$-score but similar changes in fat and fat-free mass. The low-Gl group demonstrated a significant decline in fasting plasma insulin (22.2 \pm 14.3 to $13.7 \pm 10.9 \mathrm{mU} / \mathrm{l} ; P=0.004)$ and homeostatic model of assessment-insulin resistance (4.8 \pm 3.3 to $2.9 \pm 2.3 ; P=0.007$ ), whereas the control group did not. However, general linear model showed no significant difference in insulin resistance between groups after adjusting for baseline levels, suggesting that the greater reduction in insulin resistance in the low-Gl group may be explained by higher baseline values.

CONCLUSION: Despite subtle effects on body composition, a low-GI diet may improve insulin sensitivity in obese children with high baseline insulin. A bigger study in obese children with insulin resistance could be worthwhile to confirm our findings.

C urrently, the prevalence of childhood obesity has been increasing worldwide (1). The Centers for Disease Control and Prevention reported that about $17 \%$ of children and adolescents in the United States aged 2-19 y were obese (2). Furthermore, the prevalence of the metabolic syndrome has been rapidly rising in obese children, and with it, the risk of cardiovascular disease (3). About $60 \%$ of overweight children have at least one cardiovascular disease risk factors such as hypertension, dyslipidemia, and insulin resistance. In addition, more than $25 \%$ of them have more than one type of cardiovascular disease risk factors (1). The common complications of childhood obesity are the metabolic syndrome (hypertension, dyslipidemia, insulin resistance, and type 2 diabetes), obstructive sleep apnea, nonalcoholic steatohepatitis, polycystic ovary syndrome, orthopedic complications, and premature atherosclerosis (4).

At present, we are unable to describe the exact etiology of obesity, but one of the most common causes is an imbalance between energy intake and physical activity. Treatment of obesity is difficult and can be done by several approaches, including dietary control (such as low-fat, low-energy diet), physical activity program, behavioral modification (such as generating weight reduction goal, self-monitoring, as well as positive reinforcement by parents), and medical treatment. There are many pediatric patients seeking hospital-based obesity treatment. Most of them have one or more of the complications of obesity mentioned above as well as a loss of their self-esteem and social lives. In general, conventional clinical management, including advice about low-energy diet together with increasing exercise, has not achieved satisfactory results, partially due to the restrictiveness of the diet. The glycemic index (GI) is the percentage of incremental area under the 2-h blood glucose response curve of a test food divided by the corresponding area of a reference food containing the same amount of available carbohydrate (i.e., $50 \mathrm{~g}$ of glucose). The low-GI diet, which includes foods with GI less than 55 (such as high-fiber fruits, beans, brown rice), can blunt the postprandial glucose response, slow down insulin secretion, and lead to longer satiety, hence it may be beneficial for weight reduction (5). However, the effectiveness of a low-GI diet in the treatment of pediatric obesity has not been well evaluated. There are few studies in obese children on BMI reduction (6-8) and fat mass reduction (9-12), and some of these studies showed an improvement in insulin sensitivity $(9,12)$; however, their sample sizes were quite small, and most of the studies were conducted in western countries and may not be applicable to Thai cuisine. In Thailand, the staple food is rice which has several varieties. Increased consumption of the low-GI varieties such as brown rice, thin rice noodle, or glass noodle could lower the GI and glycemic loads (GL) of the diet substantially. Moreover, most of the Thai dishes generally consist of several vegetables and fruits 


\section{Articles | Visuthranukul et al.}

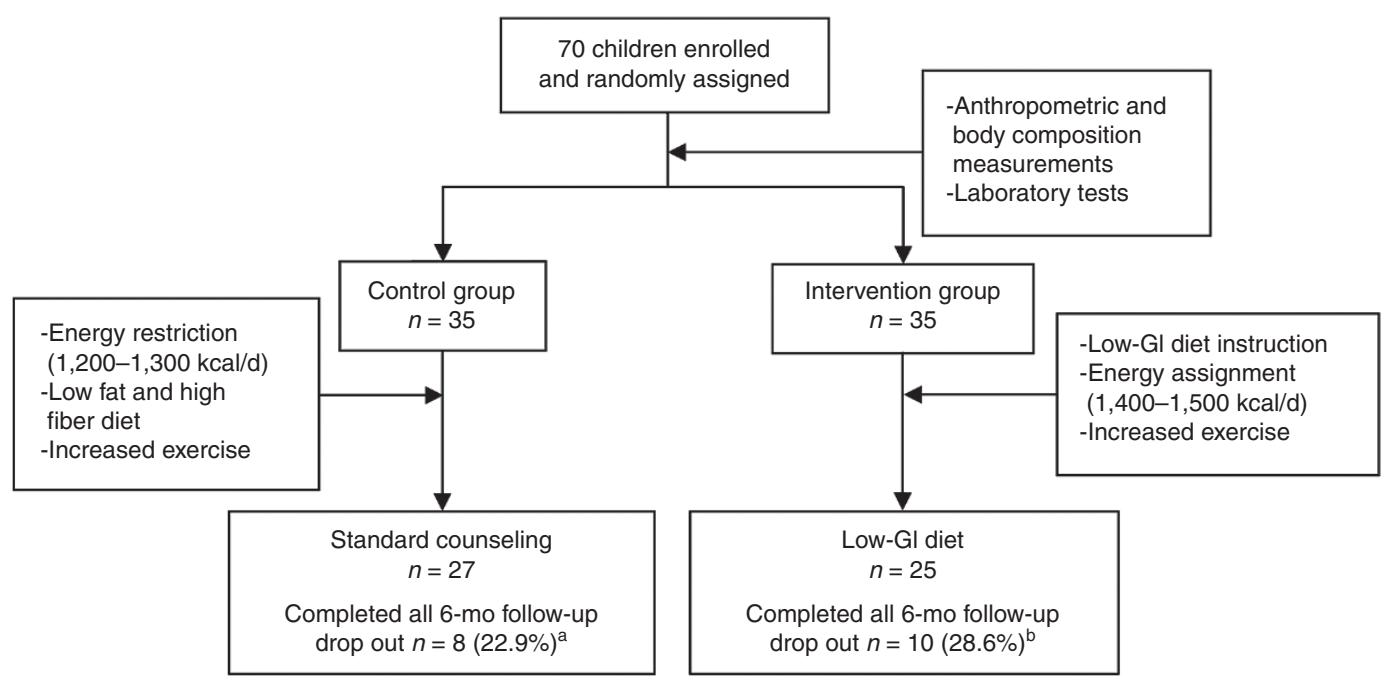

Figure 1. Flow diagram in which the progression of the participants from enrollment to the end of the intervention is shown. a 8 out of 35 participants (22.9\%) lost to follow-up. b 8 out of 35 participants (22.9\%) lost to follow-up and 2 participants out of 35 subjects (5.7\%) withdrew their consents because of the traveling problems.

which has low-GI; for examples, rose apple, guava, and dragon fruit. The objective of this study was to compare the effectiveness of a low-GI diet program and a standard counseling program in the treatment of obese Thai children.

\section{RESULTS}

A total of 70 children (47 boys, 23 girls) were enrolled and randomly allocated into two groups: 35 in the control group and 35 in the intervention group (Figure 1) between January 2010 and January 2013. Fifty-two out of 70 participants completed all six visits, 27 in the control group and 25 in the intervention group. The demographic data and baseline characteristics of both groups were compared and presented in Table 1. Mean age in the control group was $12.0 \pm 2.1 \mathrm{y}$ and in the intervention group was $11.9 \pm 1.9 \mathrm{y}$. There were no significant differences in baseline anthropometry, body composition, and laboratory tests $(P>0.05)$ except for fasting plasma insulin, homeostatic model of assessment-insulin resistance (HOMA-IR), and serum LDL cholesterol (C) which were higher in the intervention group. All analyses followed the intention-to-treat principle. The information about total energy intake and low-GI diet intake were shown in Table 2. Total energy intake in the lowGI group significantly decreased after the intervention. Along with a decline in total energy intake, daily consumption of the low-GI foods increased significantly in the intervention group (5.1 \pm 1.1 (range $3-8)$ vs. $1.5 \pm 0.8(0-3)$ items/d), whereas no change was observed in the control group $(P=0.26)$. Regarding physical activity, 13 of 27 obese children in the control group and 13 of 25 obese children in the intervention group were physically active (exercise $>3 \mathrm{~d} / \mathrm{wk}$ and $>30 \mathrm{~min} /$ time). The common feature of exercise was brisk walking in both groups.

Despite increased body weight between the first and the sixth visits in both groups, BMI $z$-score significantly decreased in the control $(P=0.015)$ and the intervention groups $(P<$ $0.0001)$. However, waist circumferences did not show significant changes in both groups $(P>0.05)$. Longitudinal changes in body composition measured by bioelectrical impedance analysis (BIA) were shown in Figure 2. There were no significant differences in the trend of fat mass index (FMI), fat-free mass index (FFMI), and percentage of fat in both groups $(P$ for trend 0.09-0.84). Within groups comparison between most metabolic syndrome profiles, namely, blood pressure, fasting plasma glucose, and serum lipid profiles, showed no significant difference between the first and the sixth visits in both groups (Table 3). Nonetheless, fasting plasma insulin and HOMA-IR significantly decreased in the intervention group $(22.2 \pm 14.3$ vs. $13.7 \pm 10.9 \mathrm{mU} / \mathrm{l} ; P=0.004$ and $4.8 \pm 3.3$ vs. $2.9 \pm 2.3 ; P=0.007$, respectively). There were no significant differences in the change in BMI, BMI $z$-score, and waist circumference between the two groups (Table 4). When the mean differences in FMI, FFMI, and percentage of fat during the study period were compared between the control and intervention groups, there were also no significant differences $(P>0.05)$. Fasting plasma insulin and HOMA-IR were much reduced in the intervention group compared with the control group. However, general linear model showed no significant difference in change of plasma insulin and HOMA-IR between groups after adjusting for baseline levels. Moreover, there was no significant interaction between baseline insulin and the treatment groups. Multiple regression analysis showed that plasma insulin in the sixth visit was decreased by $0.67 \mathrm{mU} / 1$ (95\% confidence interval: 0.44-0.91) for each increment of $1 \mathrm{mU} / \mathrm{l}$ of baseline insulin. Likewise, fasting plasma glucose and HOMA-IR in the sixth visit were decreased by $0.41 \mathrm{mmol} / \mathrm{l}$ (95\% confidence interval: $0.05-0.69$ ) and 0.72 (95\% confidence interval: $0.38-0.90)$ for each increment of $1 \mathrm{mmol} / \mathrm{l}$ of baseline plasma glucose and HOMA-IR, respectively.

\section{DISCUSSION}

This was the first randomized controlled trial in Thailand comparing the effectiveness of a low-GI diet and conventional energy restriction in the treatment of obese pediatric patients. 
Table 1. Baseline characteristics of obese children at the first visit $(n=52)$

\begin{tabular}{|c|c|c|c|}
\hline & $\begin{array}{l}\text { Control } \\
(n=27)\end{array}$ & $\begin{array}{l}\text { Intervention } \\
\quad(n=25)\end{array}$ & $P$ value \\
\hline Age, y & $12.0 \pm 2.1$ & $11.9 \pm 1.9$ & 0.84 \\
\hline Male gender, $n(\%)$ & $19(70.3)$ & $16(64.0)$ & 0.62 \\
\hline Energy intake, $\mathrm{kcal} / \mathrm{d}$ & $2,280 \pm 781$ & $2,420 \pm 755$ & 0.54 \\
\hline Low-Gl diet, items/d ${ }^{b}$ & $2.0 \pm 1.3$ & $1.5 \pm 0.8$ & 0.12 \\
\hline \multicolumn{4}{|l|}{ Tanner } \\
\hline Stage $1, \%$ & 22.2 & 32.0 & 0.37 \\
\hline Stage $2, \%$ & 33.3 & 20.0 & \\
\hline Stage $3, \%$ & 14.8 & 28.0 & \\
\hline Stage $4, \%$ & 22.2 & 20.0 & \\
\hline Stage $5, \%$ & 7.5 & 0 & \\
\hline Systolic blood pressure, $\mathrm{mm} \mathrm{Hg}$ & $113 \pm 8$ & $112 \pm 9$ & 0.63 \\
\hline Diastolic blood pressure, $\mathrm{mm} \mathrm{Hg}$ & $73 \pm 5$ & $72 \pm 7$ & 0.70 \\
\hline Weight, kg & $84.5 \pm 23.2$ & $83.8 \pm 16.0$ & 0.91 \\
\hline Height, cm & $158.6 \pm 12.1$ & $156.5 \pm 9.9$ & 0.48 \\
\hline Height $z$-score ${ }^{c}$ & $1.2 \pm 1.4$ & $1.0 \pm 1.4$ & 0.59 \\
\hline $\mathrm{BMI}, \mathrm{kg} / \mathrm{m}^{2}$ & $33.1 \pm 6.6$ & $34.2 \pm 5.8$ & 0.51 \\
\hline BMI z-score ${ }^{c}$ & $3.6 \pm 1.6$ & $3.7 \pm 0.9$ & 0.88 \\
\hline Waist circumference, $\mathrm{cm}$ & $103.1 \pm 14.9$ & $105.8 \pm 7.7$ & 0.40 \\
\hline Hip circumference, $\mathrm{cm}$ & $109.1 \pm 12.8$ & $110.7 \pm 12.8$ & 0.65 \\
\hline Mid-upper arm circumference, cm & $33.7 \pm 5.7$ & $35.1 \pm 3.9$ & 0.29 \\
\hline \multicolumn{4}{|l|}{$B \mathrm{~B}^{\mathrm{d}}$} \\
\hline Fat mass, $\mathrm{kg}$ & $31.8 \pm 14.9$ & $31.8 \pm 6.8$ & 0.98 \\
\hline$\% \mathrm{Fat}^{\mathrm{e}}$ & $36.6 \pm 8.2$ & $38.8 \pm 6.9$ & 0.31 \\
\hline Fat-free mass, kg & $53.7 \pm 13.3$ & $50.8 \pm 11.6$ & 0.42 \\
\hline $\mathrm{FMl}, \mathrm{kg} / \mathrm{m}^{2}$ & $12.4 \pm 5.2$ & $13.1 \pm 3.1$ & 0.55 \\
\hline $\mathrm{FFMI}, \mathrm{kg} / \mathrm{m}^{2}$ & $20.8 \pm 3.4$ & $20.6 \pm 3.3$ & 0.86 \\
\hline \multicolumn{4}{|l|}{ DXA } \\
\hline Fat mass, $\mathrm{kg}$ & $35.6 \pm 13.0$ & $35.5 \pm 8.7$ & 0.98 \\
\hline$\%$ Fat & $41.1 \pm 6.0$ & $42.1 \pm 4.8$ & 0.56 \\
\hline Fat-free mass, $\mathrm{kg}$ & $48.1 \pm 12.3$ & $46.9 \pm 9.3$ & 0.70 \\
\hline $\mathrm{FMI}, \mathrm{kg} / \mathrm{m}^{2}$ & $14.0 \pm 4.5$ & $14.7 \pm 3.8$ & 0.56 \\
\hline $\mathrm{FFMI}, \mathrm{kg} / \mathrm{m}^{2}$ & $18.8 \pm 2.9$ & $19.1 \pm 2.6$ & 0.66 \\
\hline \multicolumn{4}{|l|}{ Laboratory tests ${ }^{f}$} \\
\hline Fasting plasma glucose, $\mathrm{mmol} / \mathrm{l}$ & $5 \pm 1$ & $5 \pm 0$ & 0.97 \\
\hline Fasting plasma insulin, mU// & $15 \pm 8$ & $22 \pm 14$ & 0.035 \\
\hline HOMA-IR & $3.1 \pm 1.7$ & $4.8 \pm 3.3$ & 0.035 \\
\hline Serum total cholesterol, $\mathrm{mmol} / \mathrm{l}$ & $4.5 \pm 0.8$ & $4.7 \pm 0.8$ & 0.26 \\
\hline Serum triglyceride, $\mathrm{mmol} / \mathrm{l}$ & $1.1 \pm 0.5$ & $1.2 \pm 0.4$ & 0.41 \\
\hline Serum HDL (C), mmol/l & $1.2 \pm 0.2$ & $1.2 \pm 0.4$ & 0.45 \\
\hline Serum LDL (C), mmol/l & $2.7 \pm 0.7$ & $3.1 \pm 0.6$ & 0.029 \\
\hline Serum ALT, U/I & $42.3 \pm 55.5$ & $44.3 \pm 42.1$ & 0.89 \\
\hline Serum AST, U/I & $31.6 \pm 28.2$ & $31.7 \pm 20.0$ & 0.99 \\
\hline
\end{tabular}

ALT, alanine aminotransferase; AST, aspartate aminotransferase; BIA, bioelectrical impedance analysis; C, cholesterol; DXA, dual-energy X-ray absorptiometry; FMI, fat mass index = fat mass $(\mathrm{kg}) /$ height $\left(\mathrm{m}^{2}\right)$; FFMl, fat-free mass index = fat-free mass $(\mathrm{kg}) /$ height $\left(\mathrm{m}^{2}\right) ; \mathrm{HOMA}-\mathrm{IR}$, homeostatic model of assessment-insulin resistance $=(\mathrm{FI} \times \mathrm{FPG}) / 22.5 ; \mathrm{FI}$, fasting insulin concentration ( $\mathrm{mU/l}$ ); $\mathrm{FPG}$, fasting plasma glucose (mmol/).

aThese data showed means \pm SDs except for categorical variables. Chi-square was used to evaluate categorical variables. Independent sample $t$-test was used to evaluate

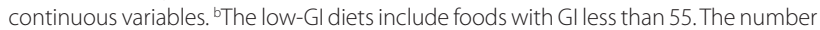
of the low-Gl diet intake was calculated as items/day by counting as types of diets/ day. CHeight $z$-score and BMI $z$-score were calculated from WHO growth reference 2007 (ref. 31). There were data from 26 participants in the control and 23 participants in the intervention groups due to some missing data for the BIA measurement. Percentage of fat was calculated from fat mass $(\mathrm{kg}) / \mathrm{body}$ weight $(\mathrm{kg}) \times 100$. There were data from 26 participants in the control group due to missing laboratory results from 1 participant. Bold text shows that intervention group was different from control group, $P<0.05$.
From the results of this study, both groups of patients had a significant decrease in BMI $z$-score during the 6-mo period. However, the body composition measured by BIA and dualenergy X-ray absorptiometry (DXA) did not demonstrate significant change from baseline in both groups. In our study, the percentage of fat and FMI measured by BIA are lower than those measured by DXA by 10 and $11 \%$, respectively. Moreover, the correlation of percentage of fat between both techniques is 0.77 , and the correlation of FMI is 0.91 . The previous study in 27 obese children from Austria reported that BIA underestimated body fat by around $12 \%$ compared with DXA which reconcile with our findings (13). Nonetheless, these differences would not change the main outcomes because the comparison between the low GI group and the control group was made within the same technique.

Our results were similar to a clinical trial on the effects of a low-GL diet vs. low-fat diet in obese Hispanic American children and adolescents (7) that reported a significant decrease in BMI $z$-score but showed no significant difference in BMI and body composition from baseline in both groups. Siegel et al. (8) found that the traffic light approach, in which the GIs of foods were simply classified as green, yellow, or red, effectively reduced BMI in obese children because of its simplicity, resulting in better adherence. There have been previous studies of low-GI diet in obese children (9-12) who had significant changes in body composition when they received instruction about this diet. A study of 14 obese children divided into two groups receiving a reduced-GL vs. reduced-fat diet by Ebbeling et al. (12) found BMI and FM decreased more in the low-GL group at 12 mo. Intensive intervention by 12 dietary behavioral therapy counseling sessions for 6 mo followed by two dietary counseling sessions for 6 mo afterward may have caused this reduction in FM, not observed in our study. Two other studies of low-GI diets have shown decreases in fat percentages that may be attributed to intensive intervention $(9,10)$. A crossover study by Pal et al. (14) of participants receiving a lowGI breakfast for $21 \mathrm{~d}$ and low-GI diet instruction for other meals demonstrated, similar to our study, a decreasing trend of fat percentage without statistical significance and higher satiety ratings before lunch during the low-GI study period. This result was comparable to another study in children on the influence of a low-GI diet on satiety (15). Our finding that participants in the intervention group had lower energy intake compared with those in the control group may be resulted from this mechanism of prolonged satiety.

We believe that the mechanism of weight loss and body fat reduction resulted from a low-GI diet is probably a gradual increase in plasma glucose that slows insulin secretion, which may subsequently cause prolonged satiety, thus decreased food ingestion, leading to a decrease in body weight and body fat (16). Conversely, the high-GI diet may quickly stimulate insulin secretion, which could then lower plasma glucose rapidly, thereby causing excessive hunger, over-eating, and lipogenesis (16). This prolonged hyperinsulinemia would have the effect of directing nutrients from oxidation to storage (6). In fact, some studies demonstrated that hyperinsulinemia due to ingestion 
Table 2. Comparison of dietary intake ${ }^{\mathrm{a}}$ within groups and between groups during the 6-mo period $(n=52)$

\begin{tabular}{|c|c|c|c|c|c|c|c|c|c|}
\hline \multirow[b]{2}{*}{ Parameters } & \multicolumn{4}{|c|}{ Control $(n=27)$} & \multicolumn{4}{|c|}{ Intervention $(n=25)$} & \multirow[t]{2}{*}{$\begin{array}{c}\text { Between } \\
\text { groups, } P \\
\text { value }^{\mathrm{d}}\end{array}$} \\
\hline & Visit 1 & Visit 6 & $P$ value ${ }^{b}$ & Difference $^{c}$ & Visit 1 & Visit 6 & $P$ value & Difference & \\
\hline Low-Gl diet, items/d $\mathrm{d}^{\mathrm{f}}$ & $2.0 \pm 1.3$ & $1.6 \pm 0.8$ & 0.26 & $-0.4 \pm 1.5$ & $1.5 \pm 0.8$ & $5.1 \pm 1.1$ & $<0.0001$ & $3.6 \pm 1.6$ & $<0.0001$ \\
\hline
\end{tabular}

aThe dietary intake data of visit 6 were the average of the data from visits $2-6$. ${ }^{\text {PPaired }} t$-test was used to compare data within groups between the first and sixth visits. Bold text shows that visit 6 was significantly different from visit 1, $P<0.0001$. 'Difference was the average of the difference between visit 6 and visit $1 .{ }^{\mathrm{d}}$ Independent sample $t$-test was used to compare

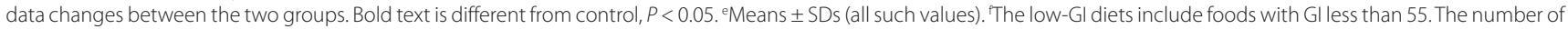
the low-Gl diet intake was calculated as items/day by counting as types of diets/day.

Gl, glycemic index.
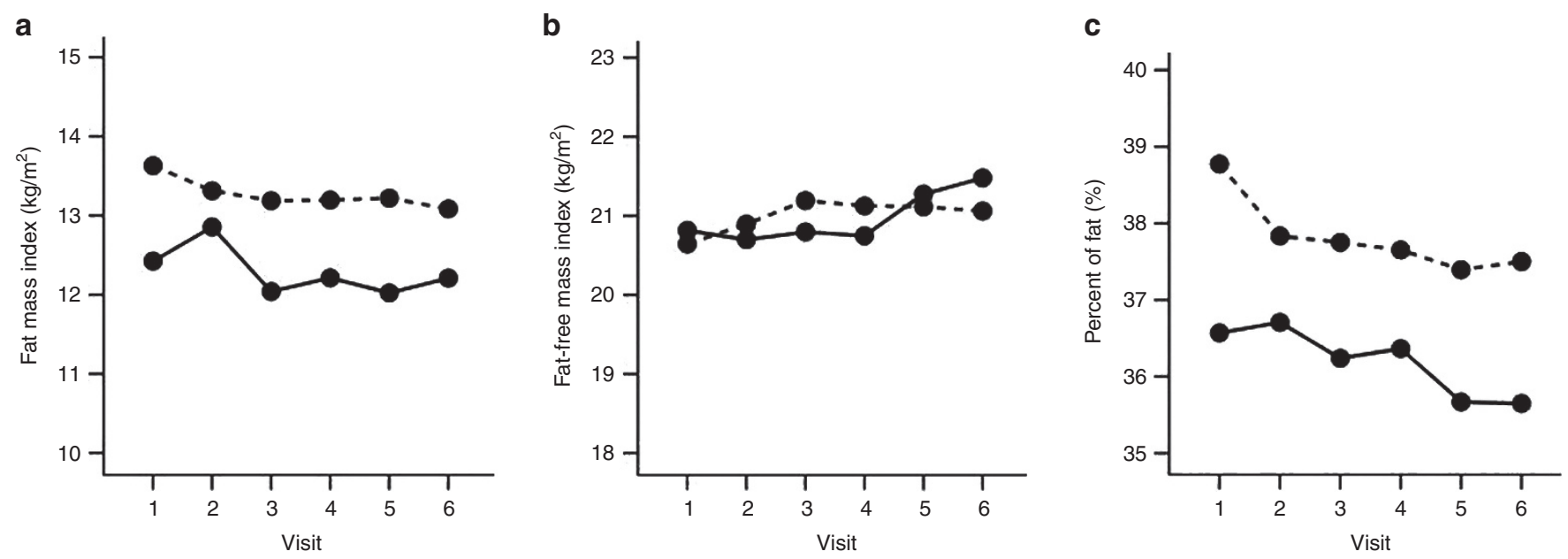

Figure 2. Body composition changes measured by bioelectrical impedance analysis. The changes are demonstrated as fat mass index (a), fat-free mass index (b), and percent of fat (c). The control group is represented by the solid line, the low-Gl diet group is represented by the dotted line. Repeated measures ANOVA was used to evaluate the changes of body composition within groups. Values are means $\pm \mathrm{SDs}$ and $P$ values are $P$ for trend of body composition changes. $P$ for trend of $\mathrm{FMl}$ : control $=0.84$. low-Gl $=0.09$; FFMl: control $=0.13$, low- $\mathrm{Gl}=0.26$; percentage of fat: control $=0.50$, low- $\mathrm{Gl}=0.10$. Fat mass index $=$ fat mass $(\mathrm{kg}) /$ height $\left(\mathrm{m}^{2}\right)$; fat-free mass index = fat-free mass $(\mathrm{kg}) /$ height $\left(\mathrm{m}^{2}\right)$; percentage of fat $=$ fat mass $(\mathrm{kg}) \times 100 /$ body weight $(\mathrm{kg})$; $\mathrm{Gl}$, glycemic index.

of a high-GI diet led to decreased hepatic fat oxidation and then increased food consumption resulting in an increase in body weight and fat $(17,18)$.

Obesity has a strong correlation with the metabolic syndrome consisted of hypertension, dyslipidemia, insulin resistance, and type 2 diabetes. Our study found a significant decrease in fasting insulin and HOMA-IR in the low-GI group but no significant change in fasting insulin or HOMA-IR in the control group. Therefore, this finding reveals that the low-GI diet might improve insulin sensitivity in obese children, similar to the data from adult population which found reduced postprandial hyperinsulinemia after the low-GI diet in obese prediabetic adults $(19,20)$. In spite of this, there were no significant differences in insulin sensitivity after a low-GI diet in some studies $(21,22)$. Shikany et al. (21) studied the effects of low- and high-GI/GL diets on coronary heart disease risk factors in 24 overweight and obese men. The participants showed no significant differences in glucose and insulin levels between both groups. This may have been because of the short study period in $4 \mathrm{wk}$ for low-GI/GL diet-similar to another study (22) - and the small sample size.

An improvement of insulin sensitivity may have been caused by reduced insulin demand, decreased glucotoxic effect on $\beta$ cells, decreased $\beta$-cell dysfunction, and prolonged suppression of free fatty acid release, which decreased their accumulation in $\beta$ cells $(23,24)$. On the other hand, a high-GI diet could conversely result in high postprandial insulin so blood glucose might rapidly decrease with an increase in counter-regulatory hormones causing declining insulin sensitivity (25). In addition, the high-GI diet also results in increasing lipid accumulation in skeletal muscle and liver which may cause insulin signaling defects and insulin resistance, and triacylglycerol accumulation in $\beta$ cells also leads to decreased insulin secretion $(23,26,27)$.

Due to the difference of baseline insulin levels between the two groups, we did general linear model and multiple regression analysis to adjust for the difference of baseline fasting plasma glucose, insulin, and HOMA-IR. The baseline fasting plasma glucose, insulin, and HOMA-IR had a greater effect on the mean difference of these results compared with the type of treatments. A better reduction in insulin resistance was demonstrated in the low-GI group; however, this appeared to be explained by higher baseline values, and the baseline level was the greater predictor of change in insulin resistance. These findings suggest that the low-GI diet could have more 
Table 3. Comparison of blood pressure and laboratory tests (within group) between the first and last visits during the 6-mo period $(n=52)$

\begin{tabular}{|c|c|c|c|c|}
\hline Group & Parameters & Visit 1 & Visit 6 & $P$ value ${ }^{a}$ \\
\hline \multirow[t]{11}{*}{$\begin{array}{l}\text { Control } \\
(n=27)\end{array}$} & $\begin{array}{l}\text { Systolic blood } \\
\text { pressure, } \mathrm{mm} \mathrm{Hg}\end{array}$ & $113 \pm 8^{b}$ & $112 \pm 8$ & 0.66 \\
\hline & $\begin{array}{l}\text { Diastolic blood } \\
\text { pressure, } \mathrm{mm} \mathrm{Hg}\end{array}$ & $73 \pm 5$ & $73 \pm 6$ & 0.78 \\
\hline & $\begin{array}{l}\text { Fasting plasma } \\
\text { glucose, } \mathrm{mmol} / \mathrm{l}\end{array}$ & $5 \pm 1$ & $5 \pm 1$ & 0.70 \\
\hline & $\begin{array}{l}\text { Fasting plasma } \\
\text { insulin, } \mathrm{mU/l}\end{array}$ & $15 \pm 8$ & $14 \pm 10$ & 0.70 \\
\hline & HOMA-IR & $3.1 \pm 1.7$ & $3.2 \pm 2.6$ & 0.91 \\
\hline & $\begin{array}{l}\text { Serum total } \\
\text { cholesterol, } \mathrm{mmol} / \mathrm{l}\end{array}$ & $4.5 \pm 0.8$ & $4.4 \pm 0.9$ & 0.51 \\
\hline & $\begin{array}{l}\text { Serum triglyceride, } \\
\mathrm{mmol} / \mathrm{l}\end{array}$ & $1.1 \pm 0.5$ & $1.1 \pm 0.6$ & 0.67 \\
\hline & $\begin{array}{l}\text { Serum HDL (C), } \\
\mathrm{mmol} / \mathrm{l}\end{array}$ & $1.2 \pm 0.2$ & $0.1 \pm 0.2$ & 0.35 \\
\hline & $\begin{array}{l}\text { Serum LDL (C), } \\
\mathrm{mmol} / \mathrm{l}\end{array}$ & $2.7 \pm 0.7$ & $2.7 \pm 0.9$ & 0.89 \\
\hline & Serum ALT, U/I & $42.4 \pm 55.5$ & $39.1 \pm 48.2$ & 0.78 \\
\hline & Serum AST, U/I & $31.6 \pm 28.2$ & $27.4 \pm 18.6$ & 0.40 \\
\hline \multirow[t]{11}{*}{$\begin{array}{l}\text { Intervention } \\
(n=25)\end{array}$} & $\begin{array}{l}\text { Systolic blood } \\
\text { pressure, } \mathrm{mm} \mathrm{Hg}\end{array}$ & $112 \pm 9$ & $109 \pm 9$ & 0.39 \\
\hline & $\begin{array}{l}\text { Diastolic blood } \\
\text { pressure, } \mathrm{mm} \mathrm{Hg}\end{array}$ & $72 \pm 7$ & $73 \pm 7$ & 0.79 \\
\hline & $\begin{array}{l}\text { Fasting plasma } \\
\text { glucose, } \mathrm{mmol} / \mathrm{l}\end{array}$ & $5 \pm 0$ & $5 \pm 0$ & 0.37 \\
\hline & $\begin{array}{l}\text { Fasting plasma } \\
\text { insulin, } \mathrm{mU/l}\end{array}$ & $22 \pm 14$ & $14 \pm 11$ & 0.004 \\
\hline & HOMA-IR & $4.8 \pm 3.3$ & $2.9 \pm 2.3$ & 0.007 \\
\hline & $\begin{array}{l}\text { Serum total } \\
\text { cholesterol, } \mathrm{mmol} / \mathrm{l}\end{array}$ & $4.7 \pm 0.8$ & $4.7 \pm 0.7$ & 0.60 \\
\hline & $\begin{array}{l}\text { Serum triglyceride, } \\
\mathrm{mmol} / \mathrm{I}\end{array}$ & $1.2 \pm 0.4$ & $1.1 \pm 0.4$ & 0.24 \\
\hline & $\begin{array}{l}\text { Serum HDL (C), } \\
\mathrm{mmol} / \mathrm{l}\end{array}$ & $1.3 \pm 0.4$ & $1.3 \pm 0.3$ & 1.00 \\
\hline & $\begin{array}{l}\text { Serum LDL (C), } \\
\mathrm{mmol} / \mathrm{I}\end{array}$ & $3.2 \pm 0.6$ & $3.0 \pm 0.7$ & 0.25 \\
\hline & Serum ALT, U/I & $44.3 \pm 42.2$ & $34.6 \pm 37.9$ & 0.27 \\
\hline & Serum AST, U/I & $31.7 \pm 20.0$ & $27.6 \pm 21.2$ & 0.38 \\
\hline
\end{tabular}

aPaired $t$-test was used to compare data between the first and sixth visits. ${ }^{b}$ Means \pm SDs (all such values). Bold text showed that visit 6 was significantly different from visit $1, P<0.01$.

ALT, alanine aminotransferase; AST, aspartate aminotransferase; $C$, cholesterol; HOMAIR, homeostatic model of assessment-insulin resistance $=(\mathrm{FI} \times \mathrm{FPG}) / 22.5 ; \mathrm{Fl}$, fasting insulin concentration (mU/l); FPG, fasting plasma glucose ( $\mathrm{mmol} / \mathrm{l})$.

beneficial effect on insulin sensitivity in obese children with high baseline insulin, although we cannot demonstrate significant interaction between baseline insulin and group by general linear model which might be due to a small sample size. Therefore, we proposed the low-GI diet instruction for obese children who have insulin resistance or diabetes which may provide additional benefits on insulin sensitivity. In the future, in order to discernibly prove this hypothesis, a trial should be
Table 4. Comparison of changes in body composition measured by DXA and laboratory tests between the control and intervention groups during the 6-mo period $(n=52)$

\begin{tabular}{|c|c|c|c|}
\hline Changes in outcomes $^{\mathrm{a}}$ & $\begin{array}{l}\text { Control } \\
(n=27)\end{array}$ & $\begin{array}{l}\text { Intervention } \\
\quad(n=25)\end{array}$ & $P$ value $^{b}$ \\
\hline $\mathrm{BMl}, \mathrm{kg} / \mathrm{m}^{2}$ & $0.4 \pm 2.0^{c}$ & $-0.2 \pm 1.6$ & 0.25 \\
\hline BMI z-score & $-0.3 \pm 0.5$ & $-0.3 \pm 0.2$ & 0.99 \\
\hline Waist circumference, $\mathrm{cm}$ & $1.1 \pm 5.6$ & $0.5 \pm 4.1$ & 0.66 \\
\hline $\mathrm{FMI}, \mathrm{kg} / \mathrm{m}^{2}$ & $0.3 \pm 1.6$ & $0.8 \pm 3.5$ & 0.45 \\
\hline $\mathrm{FFMI}, \mathrm{kg} / \mathrm{m}^{2}$ & $0.2 \pm 0.8$ & $0.8 \pm 3.9$ & 0.44 \\
\hline$\% \mathrm{Fat}^{\mathrm{d}}$ & $0.1 \pm 2.8$ & $0.1 \pm 3.0$ & 0.35 \\
\hline Fasting plasma glucose, $\mathrm{mmol} / \mathrm{l}$ & $0.1 \pm 0.4$ & $-0.1 \pm 0.4$ & 0.26 \\
\hline Fasting plasma insulin, $\mathrm{mU} / \mathrm{l}$ & $-0.8 \pm 11.3$ & $-8.5 \pm 13.5$ & 0.032 \\
\hline HOMA-IR & $0.1 \pm 2.8$ & $-1.9 \pm 3.2$ & 0.019 \\
\hline Serum total cholesterol, $\mathrm{mmol} / \mathrm{l}$ & $-0.1 \pm 0.6$ & $-0.1 \pm 0.7$ & 0.98 \\
\hline Serum triglyceride, $\mathrm{mmol} / \mathrm{l}$ & $0 \pm 0.4$ & $-0.1 \pm 0.4$ & 0.26 \\
\hline Serum HDL (C), $\mathrm{mmol} / \mathrm{l}$ & $0 \pm 0.2$ & $0 \pm 0.3$ & 0.55 \\
\hline Serum LDL (C), $\mathrm{mmol} / \mathrm{l}$ & $0 \pm 0.5$ & $-0.1 \pm 0.5$ & 0.38 \\
\hline
\end{tabular}

aChanges in outcomes were the average of the difference between visit 6 and visit 1. Independent sample $t$-test was used to compare the data between the two groups. cMeans \pm SDs (all such values). dPercentage of fat $=$ fat mass $(\mathrm{kg}) \times 100 / \mathrm{body}$ weight $(\mathrm{kg})$. Bold text showed that intervention group was different from control group, $P<0.05$

C, cholesterol; DXA, dual-energy X-ray absorptiometry; FFMI, fat-free mass index = fatfree mass $(\mathrm{kg}) /$ height $\left(\mathrm{m}^{2}\right)$; FMl, fat mass index = fat mass $(\mathrm{kg}) /$ height $\left(\mathrm{m}^{2}\right)$; HOMA-IR, homeostatic model of assessment-insulin resistance $=(\mathrm{Fl} \times \mathrm{FPG}) / 22.5 ; \mathrm{Fl}$, fasting insulin concentration (mU/l); FPG, fasting plasma glucose ( $\mathrm{mmol} / \mathrm{l})$.

conducted comparing changes in insulin resistance in obese children with high baseline insulin levels who are randomized to receive either low-GI or conventional instructions.

Before starting this study, we had anticipated that the lowGI diet participants would noticeably decrease in FMI and percentage of fat while increasing in FFMI before any change in BMI $z$-score and blood chemistry. Nevertheless, from the dietary intake data, the actual energy intake from both groups was far higher than that were instructed despite the significant changes in the amount of low-GI foods consumed in the intervention group. Thus, this might result in subtle changes in body composition. Additionally, the effect size of BMI $z$-score difference of 0.78 may be too large for this kind of intervention which might bring about less change in body composition. We used the data from 52 participants who completed all six visits without selecting some children who had good compliance because we wanted to study the effects of realistically achievable low-GI diet on all of the outcomes in their daily routine lives situation. This intention-to-treat approach may underestimate the efficacy of the low-GI diet.

In conclusion, despite only subtle effects on body composition, a low-GI diet might improve insulin sensitivity in obese children who have high baseline insulin. This finding could be applied in other pediatric settings. Instead of conventional advice of caloric restriction which may be too restrictive for some children, modest caloric reduction with substitution of high-GI foods with its low-GI varieties could be more acceptable. A possible further study may recruit a larger sample size 
with more intensive intervention such as monitoring the low-GI food consumed, evaluating hunger and satiety levels, improving physical activity recommendations and methods of assessment, and, finally, improving behavior modification techniques. This would allow accurate assessment of GI and GL of the diet and its effects on body composition, satiety levels, and insulin sensitivity.

\section{METHODS}

\section{Study Design}

This study was a prospective, randomized, controlled trial. Participants were randomly allocated (by computer-generated randomization blocks of 10) to receive either conventional obesity clinic advice or an intervention of a low-GI diet. The researcher who did not relate to data collection and data analysis used computer to generate the random allocation sequence. Other researchers enrolled participants and assigned them to interventions. The protocol was approved by the Institutional Review Board of the Faculty of Medicine, Chulalongkorn University, Thailand. The researchers described the study to the children and their parents before obtaining signed informed assents and consents (from one of the parents), respectively.

\section{Participants}

Children aged between 9 to $16 y$ with BMI higher than the International Obesity Task Force cutoff, corresponding to BMI of 30 in adulthood (28) were recruited from the King Chulalongkorn Memorial Hospital. Children who had behavioral and intellectual problems that might be an obstacle to follow the diet instruction were excluded from this study. Children who had underlying diseases that might affect a weight management program, who used drugs associated with weight increment or reduction, as well as those who attended other weight management programs were also excluded from this study.

The sample size was calculated according to the previous findings from other obesity intervention trials. The difference in BMI $z$-score of 0.78 that would represent the minimal clinically significant difference was used (29). To provide $80 \%$ power and significance of 0.05 , a minimum of 26 participants in each group was needed. Dropout rate of $25 \%$ was estimated; therefore, a total of 70 participants were required.

\section{Interventions}

For the intervention group, individual goals for weight management were set and the instruction about low-GI foods was provided. A dietitian emphasized the selection of low-GI carbohydrates, which were adapted from the table by Foster-Powell et al. (30) to fit Thai culture and their routine lives. The energy distribution was carbohydrate, $50-55 \%$; protein, $15-20 \%$; and fat, $30-35 \%$. Each visit consisted of a 2 -h, small class teaching session with parental participation (4-5 families/class). The contents varied from the first to the sixth visit, starting from portion size and food exchange, modest energy restriction, principle of GI, sources of low-GI diet, cooking demonstration of low-GI dishes, guidance about food labeling, and some games about GI of common food and beverages. The control group received conventional instructions at the Nutrition Clinic about lowenergy ( 1,200-1,300 kcal/d), low-fat ( $25 \%$ of total energy from fat), and high-fiber diet by another dietitian who gave the dietary advices with special emphasize on the energy restriction such as energy count and how to avoid high-fat Thai dishes as well as sources of high-fiber diet. In addition, the participants in both groups received the same instruction about physical activity, by increasing non-weight-bearing exercise $30 \mathrm{~min}$ per day at least three times per week, increasing physical activity in their routine lives and decreasing sedentary activity.

Both groups needed to maintain the monthly visits for 6 mo. The adherence to the nutritional education and physical activity recommendation was evaluated by using 3-d dietary records (two week days and one weekend day) and a physical activity questionnaire at each visit. All participants were examined and counseled about physical activity and life style modification strategies by a pediatrician at every visit.

\section{Outcome Measurements}

Primary outcomes. Anthropometric measurements were taken at baseline and at every visit of this study. Weight and height were measured without shoes and with light clothing using a stadiometer to the nearest $0.1 \mathrm{~kg}$ and to the nearest $0.1 \mathrm{~cm}$, respectively. Waist circumference was measured at the umbilicus level after normal exhalation with participants in standing position. Hip circumference was measured at the maximum circumference of the hips. Mid-upper arm circumference was measured the circumference at the middle point between the olecranon process of the ulna and the acromion process of the scapula. BMI was calculated as usual method weight in kilograms divided by the square of height in meters $\left(\mathrm{kg} / \mathrm{m}^{2}\right)$, and BMI $z$-score was calculated based on World Health Organization (WHO) 2007 growth reference using WHO AnthroPlus program (31).

The primary outcomes were body composition changes, which refer to FM and FFM during the 6-mo period, measured by two validated techniques. BIA (BodystatQuadscan 4000; Bodystat, Isle of Man, British Isles), which measured the body resistance to small voltage electrical current, was performed at every visit to calculate the FM and FFM. DXA (Hologic QDR Discovery A) was performed on the first and sixth visits. FMI and FFMI were then calculated by FM or FFM in kilograms divided by the square of height in meters $\left(\mathrm{kg} / \mathrm{m}^{2}\right)(32)$.

Secondary outcomes. The secondary outcomes were metabolic syndrome risk changes which were blood pressure, fasting plasma glucose, plasma insulin, and serum lipid profiles. Blood pressure was measured by blood pressure monitor (Dinamap). Venous blood was obtained after a $12-\mathrm{h}$ fast to evaluate biochemical parameters at the first and sixth visits of the study. Plasma glucose was measured by the hexokinase method (GLUCOSE, Architech; Abbott Laboratories, Irving, TX), and plasma insulin was measured by chemiluminescence (Immulite/Immulite 1000 Insulin assay, Immulite Analyzer; Abbott Laboratories). Serum total cholesterol, HDL cholesterol (C), and triglyceride were measured by enzymatic colorimetric assay (CHOLESTEROL, Architech; ULTRA HDL, Architech; and TRIGLYCERIDE, Architech; Abbott Laboratories). Serum LDL (C) was measured by homogeneous liquid selective detergent (DIRECT LDL, Architech; Abbott Laboratories). Serum aspartate aminotransferase and alanine aminotransferase were determined according to the standard of international federation of clinical chemistry (ASPARTATE AMINOTRANSFERASE, Architech and ALANINE AMINOTRANSFERASE, Architech; Abbott Laboratories). HOMA-IR was calculated from $(\mathrm{FI} \times \mathrm{FPG}) / 22.5$, FI is fasting insulin concentration (mU/l) and FPG is fasting plasma glucose (mmol/l) (33).

\section{Statistical Analysis}

SPSS version 20 was used for statistical analysis, and significance was defined as $P<0.05$. The values in the text and tables were reported as means \pm SDs. Paired $t$-test for dependent samples was used to evaluate the changes within the groups before and after the 6-mo period. Independent sample $t$-test was used to compare the changes between the two groups. Repeated measures ANOVA was used to compare the changes of FMI, FFMI, and percentage of fat in each visit in the control group and intervention group. In addition, multiple regression analysis and general linear model were used to adjust the difference of baseline insulin in both groups.

\section{ACKNOWLEDGMENTS}

The authors thank Pichita Vutthiwithayarak and Nunthida Lohawijarn for assistance with patients and data management; Sungkom Jongpiputwanich, Umaporn Suthutvoravut, Ruangvith Tantibhaedhyangkul, Piyanuch Kongtim, Alisara Sangviroon for excellent comments on the manuscript; Patricia Morgan for manuscript English editing; Kanjana Boonruang for processing and analysis of plasma insulin.

\section{STATEMENT OF FINANCIAL SUPPORT}

This study was supported by the Ratchadapiseksompoch Research Fund, Faculty of Medicine, Chulalongkorn University: grant no. RA 55/52.

Disclosure: The authors have no conflicts of interest. 


\section{REFERENCES}

1. Dietz WH. Overweight in childhood and adolescence. N Engl J Med 2004;350:855-7.

2. Centers for Disease Control and Prevention. Basics about childhood obesity: how is childhood overweight and obesity measured? 2011. (http:// www.cdc.gov/obesity/childhood/basics.html).

3. Weiss R, Dziura J, Burgert TS, et al. Obesity and the metabolic syndrome in children and adolescents. N Engl J Med 2004;350:2362-74.

4. Hoppin AG. Evaluation and management of obesity. In: Duggan CWJ, Walker WA, eds. Nutrition in Pediatrics. 4th edn. Hamilton, Ontario: BC Decker, 2008:441-53.

5. Jenkins DJ, Kendall CW, Augustin LS, et al. Glycemic index: overview of implications in health and disease. Am J Clin Nutr 2002;76:266S-73S.

6. Spieth LE, Harnish JD, Lenders CM, et al. A low-glycemic index diet in the treatment of pediatric obesity. Arch Pediatr Adolesc Med 2000;154: 947-51.

7. Mirza NM, Palmer MG, Sinclair KB, et al. Effects of a low glycemic load or a low-fat dietary intervention on body weight in obese Hispanic American children and adolescents: a randomized controlled trial. Am J Clin Nutr 2013;97:276-85.

8. Siegel RM, Neidhard MS, Kirk S. A comparison of low glycemic index and staged portion-controlled diets in improving BMI of obese children in a pediatric weight management program. Clin Pediatr (Phila) 2011;50: 459-61.

9. Fajcsak Z, Gabor A, Kovacs V, Martos E. The effects of 6-week low glycemic load diet based on low glycemic index foods in overweight/obese childrenpilot study. J Am Coll Nutr 2008;27:12-21.

10. Kirk S, Brehm B, Saelens BE, et al. Role of carbohydrate modification in weight management among obese children: a randomized clinical trial. J Pediatr 2012;161:320-7.e1.

11. Papadaki A, Linardakis M, Larsen TM, et al.; DiOGenes Study Group. The effect of protein and glycemic index on children's body composition: the DiOGenes randomized study. Pediatrics 2010;126:e1143-52.

12. Ebbeling CB, Leidig MM, Sinclair KB, Hangen JP, Ludwig DS. A reducedglycemic load diet in the treatment of adolescent obesity. Arch Pediatr Adolesc Med 2003;157:773-9.

13. Eisenkölbl J, Kartasurya M, Widhalm K. Underestimation of percentage fat mass measured by bioelectrical impedance analysis compared to dual energy X-ray absorptiometry method in obese children. Eur J Clin Nutr 2001;55:423-9.

14. Pal S, Lim S, Egger G. The effect of a low glycaemic index breakfast on blood glucose, insulin, lipid profiles, blood pressure, body weight, body composition and satiety in obese and overweight individuals: a pilot study. J Am Coll Nutr 2008;27:387-93.

15. Henry CJ, Lightowler HJ, Strik CM. Effects of long-term intervention with low- and high-glycaemic-index breakfasts on food intake in children aged 8-11 years. Br J Nutr 2007;98:636-40.
16. Venn BJ, Green TJ. Glycemic index and glycemic load: measurement issues and their effect on diet-disease relationships. Eur J Clin Nutr 2007;61:Suppl 1:S122-31.

17. Pawlak DB, Kushner JA, Ludwig DS. Effects of dietary glycaemic index on adiposity, glucose homoeostasis, and plasma lipids in animals. Lancet 2004;364:778-85.

18. Scharrer E, Langhans W. Control of food intake by fatty acid oxidation. Am J Physiol 1986;250:R1003-6.

19. Solomon TP, Haus JM, Kelly KR, et al. A low-glycemic index diet combined with exercise reduces insulin resistance, postprandial hyperinsulinemia, and glucose-dependent insulinotropic polypeptide responses in obese, prediabetic humans. Am J Clin Nutr 2010;92:1359-68.

20. Pereira MA, Swain J, Goldfine AB, Rifai N, Ludwig DS. Effects of a lowglycemic load diet on resting energy expenditure and heart disease risk factors during weight loss. JAMA 2004;292:2482-90.

21. Shikany JM, Phadke RP, Redden DT, Gower BA. Effects of low- and highglycemic index/glycemic load diets on coronary heart disease risk factors in overweight/obese men. Metabolism 2009;58:1793-801.

22. Solomon TP, Haus JM, Kelly KR, et al. Randomized trial on the effects of a 7-d low-glycemic diet and exercise intervention on insulin resistance in older obese humans. Am J Clin Nutr 2009;90:1222-9.

23. Goldstein BJ. Insulin resistance as the core defect in type 2 diabetes mellitus. Am J Cardiol 2002;90:3G-10G.

24. Zawadzki JK, Bogardus C, Foley JE. Insulin action in obese non-insulindependent diabetics and in their isolated adipocytes before and after weight loss. Diabetes 1987;36:227-36.

25. Wolever TM. The glycemic index. World Rev Nutr Diet 1990;62:120-85.

26. Shulman GI. Cellular mechanisms of insulin resistance. J Clin Invest 2000;106:171-6.

27. Adam-Perrot A, Clifton P, Brouns F. Low-carbohydrate diets: nutritional and physiological aspects. Obes Rev 2006;7:49-58.

28. Cole TJ, Bellizzi MC, Flegal KM, Dietz WH. Establishing a standard definition for child overweight and obesity worldwide: international survey. BMJ 2000;320:1240-3.

29. Belle Gv. Sample size. In: Belle Gv, ed. Statistical Rules of Thumb. New York: Wiley, 2002:29-52.

30. Foster-Powell K, Holt SH, Brand-Miller JC. International table of glycemic index and glycemic load values: 2002. Am J Clin Nutr 2002;76: $5-56$.

31. World Health Organization. WHO AnthroPlus for personal computers manual: software for assessing growth of the world's children and adolescents, 2009. (http://www.who.int/growthref/tools/en/).

32. Wells JC, Cole TJ; ALSPAC study steam. Adjustment of fat-free mass and fat mass for height in children aged $8 \mathrm{y}$. Int J Obes Relat Metab Disord 2002;26:947-52.

33. Wallace TM, Levy JC, Matthews DR. Use and abuse of HOMA modeling Diabetes Care 2004;27:1487-95. 